\title{
Revisiting 'bridging or binding': social capital and the uses of Instant Messenger (IM) and blog
}

\author{
Hong-Chi Shiau \\ Department of Communications Management, \\ Shih-Hsin University, \\ \#1 Lane17 Sec. 1, Mu-Cha Rd., Taipei, Taiwan \\ E-mail: Hongchi_2003@yahoo.com
}

\begin{abstract}
This study investigates two popular internet uses: Instant Messenger (IM) and web blogs, of which many functions were enabled by the advanced technologies. The results revealed that users in IM network are more likely to bond, whereas users in web blog network are more likely to bridge. The time spent on IM network is a strong and valid predisposition factor for bonding social capital. However, it is against prediction that the bonding or bridging social capital is not related with the size of a network.
\end{abstract}

Keywords: bonding; bridging; social capital; IM; instant message; web blog; network; civic engagement.

Reference to this paper should be made as follows: Shiau, H-C. (2008) 'Revisiting 'bridging or binding': social capital and the uses of Instant Messenger (IM) and blog', Int. J. Electronic Democracy, Vol. 1, No. 1, pp.85-97.

Biographical notes: Hong-Chi Shiau ( $\mathrm{PhD}, 2002$, Temple University) is an Assistant Professor in the Department of Communications Management at Shih-Hsin University in Taiwan. His research interests include media globalisation, popular culture and audience reception - how global media texts were re/produced in the local and how the local re/negotiate their identities. His previous publication focused on how the rise of new technologies has had changed under-privileged people.

\section{Introduction}

Many scholars have lamented the decline of social capital, civic and political participation in US society. Based on a range of indicators of civic engagement, for instance, Putnam (1995a, 1995b, 2000) asserted that the decline of social capital had become serious grounds for concern. In response to the concern, scholars investigating the relationship between the internet use and social capital follow theoretical frameworks handed down mostly from television research. The debate was contentious: on the one hand, a positive connection between internet use and social capital is found, and the internet use, in general, plays a supplemental, rather than supplanting role for face-to-face and face conversation (Wellman and Gullia, 1999). Additionally, the time spent on internet use has cut off television viewing, not civil-related activities (e.g., Kestnbaum et al., 2002; UCLA Center for Information Policy, 2001). The internet can be seen as a 
working platform of civic engagement; besides, the interconnectivity nature of the internet helps to develop social contacts and build social support networks, thus it is well believed that the internet can enhance building social capital potentially. On the other hand, Nie (2001) and Nie and Erbring (2002) is a proponent asserting that as internet use increases, offline social activities decline. Antidotal evidences also revealed cases of addiction or withdrawal in a virtual nutshell among heavy users. It has ground for some speculations that the rise of internet may destroy social networks and lowers social trust (Putnam, 1995, 2000; Wellman et al., 2001; Kraut et al., 2002).

As internet technologies became advanced, studies have begun to find that the effects of internet use are more than straightforward. For instance, internet use was found to amplify the existing social patterns (e.g., Hampton and Wellman, 2001; Kavanaugh and Patterson, 2001; Kraut et al., 2002). Zhang and Chia's (2006) study echoes the assumption, indicating that time spent in reading newspaper and watching public affairs on television was positively correlated with political participation, whereas frequency of internet use and entertainment TV viewing was not. The results also showed no correlation between internet use and civic participation. The study suggests that informational uses of the internet are positively related to the accumulated social capital, whereas social-recreational uses are negatively related to these civic indicators, although the size of associations is generally small (Shah et al., 2001). Along the same line of debate, Best and Krueger (2006) argued that these categorisations of use into informational and entertainment are too simplistic. In his research, it is the level of online interaction with people met on the internet not the use, positively relates to common indicators of social capital, such as generalised trust. In spite of varying perspectives, some online activities appear more associated with the enhancement of social capital than others. For instance, participation in online communities and use of the internet among informal groups could counter negative aspects of internet use (Kobayashi et al., 2006), and online reciprocity has a positive effect on intention to participate in online civic discussion (Dutta-Bergman, 2005).

In the same vein, studies of social psychology have sought to explain how and why some people participate more than others are. Livingstone et al. (2005) suggests that visiting civic websites depends primarily on demographic factors - older, middle-class girls being most likely to visit these sites and have more in-depth civic involvement. She identifies three groups of young people - interactors, the civic-minded and the disengaged - each of which is distinctive in its social context and approach to the internet.

Based on a premise positing that different internet activities relate to the varying level of accumulation of social capital, scholars attempt to understand specific positively and negatively - affecting online activities and examine the users' motives. However, the effects of the internet are complicated. The heaviest users of the internet are the least committed to online community. Second, researchers were interested in knowing if there is a spillover of online social capital into offline arenas. As format and content of online communication have become increasingly diversified and sophisticated, studies on media use have gradually found that people's interaction on online supplements their face-to-face and telephone communication without increasing or decreasing it. As suggested, the internet is becoming normalised, as it is incorporated into the routine practices of everyday life (Kobayashi et al., 2006). However, despite the positive association between offline and online participation in voluntary organisations and 
politics, heavy internet use is not associated with increased participation in voluntary organisations and politics (Katz and Rice, 2002).

\section{East Asia, technological advancement and civic engagement}

Although common categorisation of internet use: entertainment-related or information-related is useful in discussing civic participation, it is becoming plausible as a result of the explosive growth in connectivity and the changing internet use in the content and interactive process. While studies concerning civic engagement and internet use have been at the centre of discussion, few have incorporated some specific functions enabled by the broadband technologies into their analyses. In fact, cyberspace environment and interface landscape have changed enormously, thanks for improved compression and broadband technologies. Some traditional limitations, such as connectivity or slow audio-visual file transmission, have been largely overcome in many East Asian countries. While the issue of digital divide - the disparities between the haves and have-nots - remains manifesting itself in varying manners across the world, the issues of media literacy and civic empowerment are apparently more impelling in countries where most citizens are digitally connected. The uses of internet have been complicated as boundaries among media have been blurred (Kahney, 2003). For instance, mobile phones with internet functions, online communities, and web-based developments like blogging, e-games, and e-Bay are increasingly prevalent. These components of 21 st century life in the 'connected economy' have become important technological actors complicating the earlier analyses. As the broadband technologies were still in infancy, the essential aspect of internet activities was surfing on the web and creating texts on emails. Since high-speed connection has become the platform, chatting, games and audio-visual file sharing are increasingly becoming defining characters of internet use.

The earlier studies also left some current issues unchecked. Young people are participating in various online activities, which sometimes can happen simultaneously. Choices of activities for communication and entertainment are abundant: peer-to-peer connection, gaming, webpage/content creation and audio-visual (e.g., Youtube) file viewing are examples. Information-related activities are also abundant too: online polling and voting and visiting civic/political websites are common.

Given the aforementioned changes, researchers have illustrated cases exemplifying how the internet has successfully (or unsuccessfully) helped to build up a network and facilitated a sense of connectedness and why. Empirical evidences have demonstrated that significant communal features on some online discussion forums are arenas through which debates and different viewpoints are visible (Hodkinson, 2007). Despite lacking systematic exploration, the potential of enhancing social trust and connectedness, two essential dimensions of social capital, for using online forums has been illustrated in case studies revolving election and political campaign, a public space founded by institutions.

\section{Instant (MSN) Message and blogs}

Since the dawn of new millennium, South Korea, Taiwan and other Asian tigers have significantly advanced telecommunications infrastructure and even outperformed Japan 
or most of their western counterparts ${ }^{1}$ (ITU, Annual Report, 2007). As these democratic societies became technologically advanced, their citizens should be potentially better equipped in participating civic issues through the internet. It is in this context my study intends to investigate how two of the commonly used internet functions relate to social capital. On the one hand, the high-speed internet can enable a relatively more interactive and carefree cyberspace geared towards communication or entertainment among strong-tied and solid-connected communities. Thus, participants could be dragged to a 'fun house' where civic engagement seldom falls in the terrain of emphasis. As admonished by media literacy scholars, in contrast to the information-focused uses at the centre of public and policy agendas, these communication and entertainment focused activities, often neglected, are taking more time out from the citizens in the highly technologically driven society. Technological advancement can enhance, but also more likely impair civic participation. On the other hand, as technological barriers remove, a larger number of participants can enter the public sphere at the same time interacting and voting. It has also grounds for speculating an improvement for civic participation.

Putman concepts of 'bridging' and 'bonding' provide a useful framework for evaluating various outcomes of the aforementioned technological changes. According to Putnam (2000), bridging occurs when individuals from different backgrounds make connections between social networks. As a result, bridging enables individuals to broaden social horizon or world views, or open up new opportunities for information. In contrast, bonding occurs when strongly tied individuals provide emotional or substantial support for one another. The continued reciprocity found in bonding social capital provides strong emotional and substantive support and enables mobilisation. Its drawback is assumed to be insularity and out-group antagonism (Kobayashi et al., 2006).

Subsequent research in the field of organisational studies has followed that Putman's classifications discovering that the type of relationships within the social network can predict different kinds of social capital. The connections in the so-called 'weak-tie networks' yield Putnam's bridging social capital; showing that more ties are better than fewer ties (Friedkin, 1982), and that the diversity of the weak-tie network leads to greater gains (Burt, 1983). Strong ties, meanwhile, are still important in affecting change within organisations (Krackhardt, 1992).

Some studies have paid attention to the consequences of various internet uses. Email use was first of interest. Researchers suggest that email use between strangers (i.e., those with very weak ties) in a large organisation has been found to lead to information gains (Constant et al., 1996), and workers and organisations have been shown to benefit from supporting computer-mediated weak-tie connections (Pickering and King, 1995). Besides, Kobayashi and Ikeda (2004) offer an insightful analysis of the correlation between some specific internet uses and civic participation. Their research indicates that one-to-one exchange of emails by mobile phone through intimate networks is negatively associated with social participation and issue involvement, while the use of email by PC is positively associated. Because of various functions and bases of internet use, its underlying social ramifications and consequences are different. The email exchanges by mobile phone are often among one another intimate enough, usually involve mainly strong-tied networks. 
It is in this context, this study acknowledges that some types of internet use have become more frequent in some societies owing to the changes in media landscape. Earlier studies analysing internet use have rarely incorporated these changes into account. For instance, Instant Messengers (IMs) ${ }^{2}$ (IM, MSN is the most popular in Taiwan) are nearly becoming the most common among several possible internet uses. Along with the rapidly increasing use of online journal style web logs ('blogs') in Taiwan, other internet uses (e.g., e-ail, blackberry, and web page surfing) have been significantly curtailed. In response to these changes, this study attempts to examine these two specific internet uses recognising that these changes in media use may potentially impact and restructure online communities and social network in East Asia.

These two defining internet uses have different connotations for the underlying motives of media use. Rated as the most common internet use in Taiwan, IM often occurs among a close network in which one is tied with another (Taiwan's III report). The members in IM network are selected by an individual deliberately and consciously, which in a sense set a clear interpersonal boundary between insiders and outsiders. On the other hand, one of the most popular forums hosted by individuals and organisations, web blogs have attracted heterogeneous individuals from diverse backgrounds. The use of web blogs seems to exemplify the weak-tie network through which the individual having weak offline relationships can access and interact. The structures of network between IM and Blogs differ in the sense that the boundary of IM is clearly defined by individuals. Those who included in the IM network are considered to be 'in-group,' and accordingly the tie is stronger.

On the other hand, another important internet use, also widely discussed but rarely paired with IM use, is web blog. Frequently accessible to everyone with a forum, web blogs can become the public sphere where participants interact and discuss civic issues. ${ }^{3}$ By responding to or compromising with heterogeneous viewpoints, people could develop persuasive skills and negotiating powers fundamental to promoting social capital online, which is why earlier researchers recognise the importance of discussion forums in facilitating a free and democratic society. Initially, centred upon the individual rather than the group, yet increasingly interactive and socially oriented, web blogs (interactive online journals) appear particularly consistent with the individualised public forum (Ojala, 2005). Because of its nature of open access and low cost, the number of blogs in Taiwan has increased drastically since its conception. It attracts not only individuals to speak out, but also community-based activists, non-profit organisers, politicians and civil right advocates all to utilise and organise their forum to encourage discussions in public issues. The creators of Blogs, in a respect, have increasingly become moderators for an online community revolving around the same interest. Lively exemplified in countries across the world (e.g., South Korea and Mexico), 'civic journalism,' usually weaving a group of web blogs, and sometimes can form a new autonomous, assertive and politically diverse journalism. It is thus believed that web blogs could be systematically used to enhance civic participation and government accountability to citizens. The civic objectives expressed by its principal practitioners can be hard more easily. In this case, Hughes (2006) offers an example of how the Mexican citizen journalism taken over (though not completely) from the authoritarian model that dominated for most of the 20th century. Another well-documented example is Ohmynews.com in South Korea: with the help of more than 26,000 registered citizen journalists; this collaborative online newspaper has emerged as a direct challenge to established media outlets in just four years. 


\section{Hypotheses}

Do these two defining media uses positively or negatively associate with social capital? Both media uses are two of the most popular internet uses in Taiwan, probably as well as in many Asian countries. Given these obvious differences in nature as well as the discovery found earlier, my research hypothesises that the more involvement with IM (pertaining to the online interaction with offline existing friends) may associate negatively with 'bridging', and aspect of social capital. It creates the in-group biases - one who act favourably towards the person is included and react unfavourably towards or ignore people outside the group. Because of the pre-occupation with the existing interpersonal network, the heavy users of IM users are more likely to confine themselves in a small nutshell, seldom looking beyond the network to explore public issues on the horizon. In contrast to the confinement, the open nature of blogs more likely attracts people from diverse backgrounds. Given this, individuals in the network have to engage civic debate and see things from different perspectives. Furthermore, Blogs have become the easiest and common way for a civilian to participate in the collective production of internet content independent of political and commercial influence. We may well hypothesise that the use of Blogs is positively associated with 'bridging' and negatively with 'bonding.' The following are five hypotheses of this research.

H1: The use of IM and Blogs has become dominant uses during the time online.

H2: IM use is related to a decrease in 'bridging' (encountering heterogeneous others).

H3: IM use is related to an increase in 'bonding' (emotionally connected with others).

H4: Blog use is related to an increase in 'bridging' (encountering heterogeneous others).

H5: Blog use is related to an increase in 'bonding'.

\section{Methods}

\subsection{Participants and procedures}

Taiwanese college students $(N=238)$ enrolled in the following classes at Shih-Hsin University: Communication Competencies, Media Literacy and General Psychology, were sampled on a volunteer basis with incentives. The Social Capital Scale was translated from English into Chinese and was revised to ensure of a full comprehension among the respondents in the study. All the surveys were conducted in Chinese. The former two classes were taught by the researcher, the latter was taught by the researcher's colleague. The former two classes are college-wide requirement. However, students are drawn from reasonably diverse backgrounds since media literacy is an evening course offered to professionals working during the day aged between 24 and 40; whereas, the remaining two classes are freshmen, sophomores or juniors aged between 18 and 22. These subjects are equally educated. Gender is controlled evenly. After briefing the content and purpose of the survey, the researcher distributed traditional 
hard copy of surveys in classes under the consent of participants. These results were collected.

\section{Measurement}

\subsection{Independent variables}

Demographic measures include gender and age. Sample students are aged between 18 and 30 and approximately equally educated.

Time online. The total duration spent online weekly.

The use of Instant Message (IM)

All the students use MSN in Taiwan as the IM choice. The use of IM in this study is composed of several dimensions:

- How many hours the respondents used weekly?

- How many contact members on the list do the respondents have?

The use of blogs

All the students know Blogs as a form of internet use. The use of Blogs in this study examines several dimensions:

- How many hours the respondents used (including posting, reading and responding) weekly?

- How many people they become acquainted with?

\subsection{Dependent variables}

Online bridging vs. binding social capital

Extending Putnam's (2000) arguments and drawing upon existing questions from previous scales, the Internet Social Capital Scales (ISCS) developed by Williams (2006) has presented a handy means of understanding and measuring social capital. The ISCS intended to compare across two dimensions: bridging vs. bonding and online vs. offline. This research focuses on online use and selects five items out of the ten by adjusting Taiwan's local cultural environment. The rectified items for bridging and bonding are listed as below. Therefore, the subscale for bridging and bonding measures is used to evaluate two different media uses (IM vs. Blog), resulting in four subscales.

\begin{tabular}{ll}
\hline Bridging subscales \\
\hline 1 & Interacting with people using IM/Blogs makes me want to try new things \\
2 & $\begin{array}{l}\text { Interacting with people using IM/Blogs makes me interested in what people unlike me are } \\
\text { thinking }\end{array}$ \\
3 & Talking with people using IM/Blogs makes me curious about other places in the world \\
4 & Interacting with people using IM/Blogs offers me opportunities to advocate what I believe \\
5 & Interacting with people using IM/Blogs reminds me that everyone in the world is connected \\
\hline
\end{tabular}


Bonding subscales

1 There are people using IM/Blogs with whom I usually dine out not for business purpose

2 There are several people using IM/Blogs I trust to help solve my problems

3 There is someone using IM/Blogs I can turn to for advice about making very important decisions

4 There are people using IM/Blogs that I feel comfortable talking to about intimate personal problems

5 When I feel lonely, there are several people using IM/Blogs I can talk to

\section{Result}

\subsection{Changes in internet use}

This study recognises that the simultaneous media use has become an important trend. It is reasonable to assume that internet users are not devoted to a singular online activity (As seen in Figures 1 and 2). It is also too naïve to assume that users may not use the internet along with other media simultaneously. For instance, abundant examples on daily life have shown people watching TV while surfing on the internet. Given this, my study intentionally does not make each internet use exclusive. As seen below, IM use has made up nearly one-thirds of internet use as the leading online activities. This is in part due to that most users sign in MSN messenger as soon as they are connected. It is difficult to measure continuous time use of IM since the interactions occurring are frequently irregular. However, most Taiwan's respondents have reported that they leave their IM on whenever they are online. Although not as dominant, the use of blogs is common - it is even more frequently used than emails for Taiwanese users. The details can be seen as below:

Figure 1 Time spent on different internet uses (items listed are not mutually exclusive) (see online version for colours)

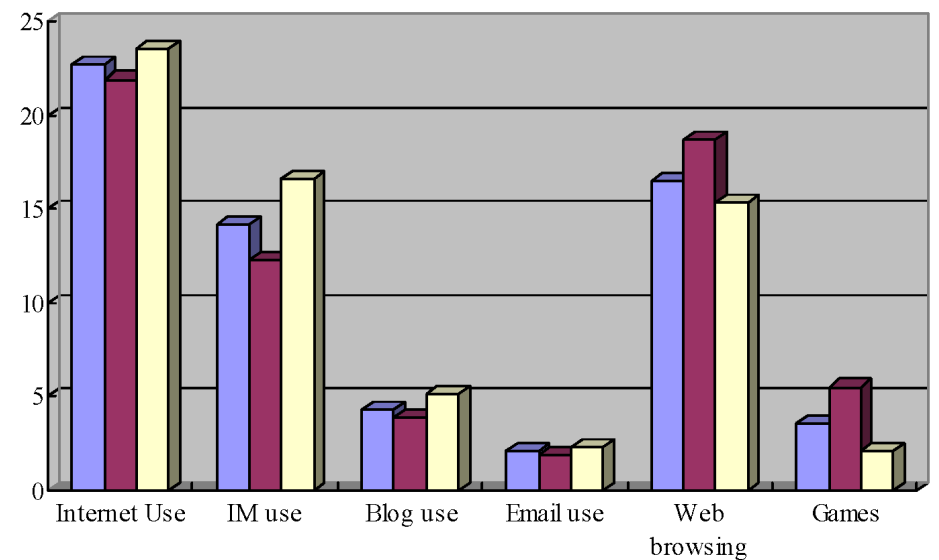


Figure 2 Frequency and distribution for number of users in the network of IM and blogs (see online version for colours)

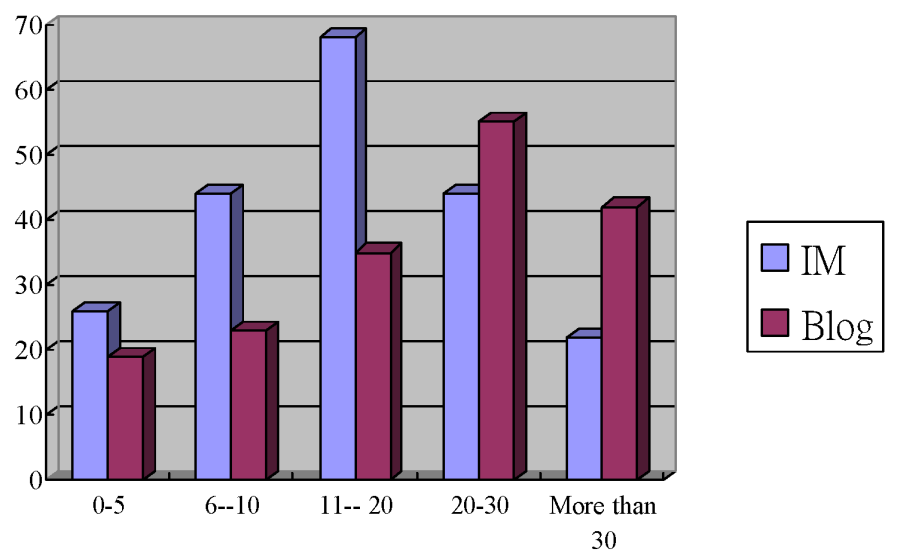

As theories suggest, a small number of contact members in a network are more likely to bind. As the number increases in a network, people tend to bridge. The following figure (Figure 2) indicates that the size of IM network and web blog varies. The average number of users in web blog network is larger with an average of 29.6, whereas the number of people interacting in IM network is smaller (mean value: 21.8). The result supports my hypothesis that IM network is smaller in size when compared with blogs. However, for a further regression analysis, dummy variables of five groups were created: $0-5,6-10$, 11-20, 21-30 and more than 30. The scale is more sensitive in small size. If a number is less than ten, it can fall in two groups. Both can be considered as small networks as the chart divides $0-10$ into two groups. Approximately, 30\% of users maintain a number smaller than ten. Besides, the size of number in blogs varies and can be as large as 77 .

As shown in Table 1, the total of two specific internet uses are generally more associated with bonding (3.1034 out of a possible 5) than bridging (2.0023 out of a possible 5). As predicted, respondents in IM communities are significantly more likely to bond than in Blogs communities. However, no significant difference between the respondents in Blogs and IM networks is found.

The finding of this study is consistent with earlier findings that the more time online, the more total bridging and bonding social capital is formed. The stepwise regression analysis examines each of the subgroups independently so as to understand factors affecting whether an online network is more inclined towards creating bridging or bonding capital. Significant variable includes type of networks (IM vs. blogs) and the size. As predicted, the results revealed that users in IM network are more likely to bond $(\beta=0.242, p=0.023)$, whereas users in web blog network are more likely to bridge. The time spent on IM network is a strong and valid predisposition factor for bonding social capital $(\beta=0.337, p=0.001)$ : the more time a user spends on IM, the more bonding social capital she/he enjoys. However, it is against prediction that the bonding or bridging social capital is not related with the size of a network. 
Table 1 Results of one-way analysis of variance on the basic descriptive bridging $(n=228)$ vs. bonding $(n=196)$ social capital in different internet uses

\begin{tabular}{llccc}
\hline Variables & Means & $d f$ & $F$ & Significance \\
\hline Online bridging social capital & 2.2523 & 1 & 3.921 & 0.129 \\
IM & 2.2334 & & & \\
Web blog & 2.2822 & & & \\
Online bonding social capital & 3.1034 & 1 & 40.121 & 0.000 \\
IM & 3.9221 & & & \\
Web blogs & 2.2011 & & & \\
\hline
\end{tabular}

\section{Discussion}

Earlier research tends to appropriate internet use as a category and focuses on whether the internet differs in the way it helps or hinders the formation of social capital. The earlier interest was from an assumption that most online interactions lack the myriad social and physical cues one has in face-to-face communication (Walther, 2006). The cost for participating in online interactions is lower, since it is usually easier to enter and exit, thus the interaction is shallower and offers less bonding social capital (Galston, 1999). However, as internet technologies advance, the underlying assumptions are not as valid. For example, IM is presently used by all Taiwanese college respondents. Thanks for the high penetration of broadband connection, the respondents of this research frequently use audio-visual function to complement their other communication choices (e.g., cell phone) and reduce the cost. The popularity of IM network formed among existing interpersonal networks has in fact challenged the earlier conceptualisation of internet use. IM use can be complicated, it can occur with or without audio/visual cues. Furthermore, small-sized network is not found always easier for the formation of bonding social capital, although it is usually true. Rather, the tie in a size of network smaller than five is weaker than that of 6-10. Similarly, heavy traffic on a web blog does not necessarily transcend to the formation of bridging social capital. Although widely used as a forum to attract discussions on civic issues, personal blogs are not usually associated with the formation of bridging social capital geared towards connecting heterogeneous others. It is also more likely that blog users create their own site to keep personal journals and maintain their photo albums. It is true that the connectivity, which the convergence of devices and the greatest predisposition to the use of internet, has been overcome in many societies. Nevertheless, there is a more noticeable friendship network residing in individualised IM and blog communities. It is true that young people are awakening to solidarity and altruism, however occasionally and sporadically. These gestures, often considered as predisposition for civic participation, are seldom connected with political life and with further mobilisation for civil involvement.

These research attempts to go beyond the purview confined mostly in Anglo-Saxon context. The use of $\mathrm{IM}^{4}$ and how it is related to the accumulation of social capital in Asian context have been under-explored. This can be evidenced by the overwhelming attention on use of the web blogs for a wide spectrum of civic participation-related activities, such as electoral campaigns, political public relations and civic empowerments in journal articles. To the contrary, the use of IM was comparatively scarce, with a focus 
more inclined towards non-political issues. The strong positive linkage between IM use and bonding social capital suggests how the network of IM helps to maintain relations. However, it is not "the more, the merrier". Neither the formation of bonding nor bridging social capital is related with the size of a network. This may suggest that a large network does not necessarily lead to a higher degree of social capital. Sometimes, smaller network could have stronger payoffs.

A problem with the current project is its use of a convenience sample. College students used in this study might possess better computer skills and internet access than the general public, and this might have influenced the outcome of the study.

As internet technologies advance, online social network formulated may play a role different from that described in early literature on virtual communities. As seen in the results, most users have used more than one use (e.g., IM, web surfing and email composing simultaneously). This study suggests that some specific uses on the internet are associated with certain type of social capital. Web blogs are more likely used to become acquainted with heterogeneous others. For the studies in the future on social capital, it would be useful to examine how a specific use mediating civic opinion functions. For instance, previous research shows that deliberation can change people's opinions dramatically (e.g., Luskin et al., 2002). Based on this assumption, how does opinion change take place after deliberation in IM network and web blogs?

\section{References}

Best, S. and Krueger, B.S. (2006) 'Online interactions and social capital: distinguishing between new and existing ties', Social Science Computer Review, Vol. 24, No. 4, pp.395-410.

Burt, R.S. (1983) 'Range', in Burt, R.S. and Minor, M.J. (Eds.): Applied Network Analysis, Sage, Beverly Hills, pp.176-194.

Constant, D., Sproull, L. and Kiesler, S. (1996) 'The kindness of strangers: the usefulness of electronic weak ties for technical advice', Organization Science, Vol. 7, No. 2, pp.119-135.

Dutta-Bergman, M.J. (2005) 'Access to the internet in the context of community participation and community satisfaction', New Media and Society, Vol. 7, No. 1, pp.89-109.

Friedkin, N. (1982) 'Information flow through strong and weak ties in inter-organizational social networks', Social Networks, Vol. 3, No. 4, pp.273-285.

Galston, W. (1999) Does the Internet Strengthen Community?, Available at: www.pauf.umd.edu? IPPP/fall1999/internet_community.htm, Accessed 20 June, 2007.

Hampton, K. and Wellman, B. (2001) 'Long distance community in the network society: contact and support beyond netville', American Behavioral Scientist, Vol. 45, pp.476-495.

Hodkinson, P. (2007) 'Interactive online journals and individualization', New Media and Society, Vol. 9, No. 4, August, pp.625-650.

Hughes, S. (2006) Newsroom in Conflict: Journalism and the Democratization of Mexico, University of Pittsburg Press.

Kahney, L. (2003) 'Citizen reporters make the news', Wired News, 17 May.

Katz, J.E. and Rice, R.E. (2002) Social Consequences of Internet Use: Access, Involvement, and Interaction, The MIT Press, Cambridge, Massachusetts.

Kavanaugh, A.L. and Patterson, S.J. (2001) 'The impact of community computer networks on social capital and community involvement', American Behavioral Scientist, Vol. 45, pp.496-509.

Kestnbaum, S., Robinson, J.P., Neustadtl, A. et al. (2002) 'Information technology and social time displacement', IT and Society, Vol. 1, pp.21-37. 
Kobayashi, T. and Ikeda, K. (2004) Does Internet usage Increase the Amount of Social Participation? A Comparison of the Social use of the PC and Mobile Phone, JSICR Annual Report 2003, pp.39-49.

Kobayashi, T., Ikeda, K. and Miyata, K. (2006) 'Social capital online: collective use of the internet and reciprocity as lubricants of democracy', Information, Communication and Society, Vol. 9, No. 5, October, pp.582-611.

Krackhardt, D. (1992) 'The strength of strong ties: the importance of philos in organizations', in Nohria, N. and Eccles, R. (Eds.): Networks and Organizations: Structure, Form, and Action, Harvard Business School Press, Boston, MA, pp.216-239.

Kraut, R., Kiesler, S., Boneva, B., Cummings, J., Helgeson, V. and Crawford, A. (2002) 'Internet paradox revisited', Journal of Social Issues, Vol. 58, No. 1, pp.49-74.

Livingstone, S., Bober, M. and Helsper, E.J. (2005) 'Active participation or just more information?', Information, Communication and Society, Vol. 8, No. 3, September, pp.287-314.

Luskin, R.C., Fishkin, J.S. and Jowell, R. (2002) 'Considered opinions: deliberative polling in Britain', British Journal of Political Science, Vol. 32, pp.455-488.

Nie, N. (2001) 'Sociability, interpersonal relations, and the internet', American Behavioral Scientist, Vol. 45, pp.420-435.

Nie, N.H. and Erbring, L. (2002) 'Internet and society: a preliminary report', IT and Society, Vol. 1, pp.275-283.

Ojala, M. (2005) 'Blogging: for knowledge sharing, management and dissemination', Business Information Review, Vol. 22, No. 4, December, pp.269-276.

Pickering, J.M. and King, J.L. (1995) 'Hardwiring weak ties: interorganizational computermediated communication, occupational communities, and organizational change', Organization Science, Vol. 6, No. 4, pp.479-486.

Putman, R.D. (2000) Bowling Alone: The Collapse and Revival of American Community, Simon \& Schuster, New York

Putnam, R.D. (1995a) 'Bowling alone: America's declining social capital', Journal of Democracy, Vol. 6, pp.65-78.

Putnam, R.D. (1995b) 'Turing in, turning out: the strange disappearance of social capital in America', Political Sicence and Politics, Vol. 28, No. 4, pp.664-683.

Shah, D., Kwak, N. and Holbert, R. (2001) 'Connecting' and 'disconnecting' with civic life: patterns of internet use and the production of social capital', Political Communication, Vol. 18, No. 2, pp.141-162.

UCLA Center for Information Policy (2001) The UCLA Internet Project: Year Two, Available at www.ccp.uclas/pages/newsTopics.asp?id=27, Accessed 28 July, 2007.

Walther, J. (2006) 'Noverbal dynamics in computer-mediated communication', in Manusov, V. and Patterson, M. (Eds.): The Sage Handbook of Nonverbal Communication, Sage, Thousand Oaks, CA, pp.461-480.

Wellman, B. and Gullia, M. (1999) 'Net surfers don't ride alone: vitual communities as communities', in Wellman, B. (Ed.): Network in the Global Villege, Westview, Boulder, CO, pp.331-366.

Wellman, B., Haase, A.Q., Witte, J. and Hampton, K. (2001) 'Does the internet increase, decrease, or supplement social capital?', Social Networks, Participation, American Behavioral Scientist, Vol. 45, No. 3, pp.436-455.

Williams, D. (2006) 'On and off the net: Scales for social capital in an online era', Journal of Computer-Mediated Communication, Vol. 11, No. 2, article 11, available at http://jcmc. indiana.edu/vol11/issue2/williams.html

Zhang, W. and Chia, S. (2006) 'The effects of mass media use and social capital on civic and political participation', Communication Studies, Vol. 57, No. 3, pp.277-297. 


\section{Notes}

${ }^{1}$ comScore also released the top 15 countries ranked by average hours spent online per visitor for March 2006, as a measure of engagement. Israel led the list, with the average user spending 57.5 hours online during the month - twice as much time compared with the average person in the USA, which did not rank in the top 15 countries. Rounding out the top 5 were Finland, South Korea, the Netherlands and Taiwan - all countries with high broadband penetration.

${ }^{2}$ While teaching communication competencies in a computer lab, I was surprised that my students all quickly sign in and start chatting one another. Based on my informal survey with my students, IM (Instant Message) is the most common use of online activity. Nearly, all students sign in as soon as they turn on their personal computer (in the case of Taiwan, all my students own their personal computers.).

${ }^{3}$ Wretch is a site offering free space for web blogs in Taiwan. Shortly after its establishment, it has attracted the second largest amount of visits following yahoo Taiwan, the largest portal site.

${ }^{4}$ Microsoft MSN released an online article in Chinese indicating the penetration of IM use in Taiwan was highest in 2006. This rate might be over-estimated since IM function offered by AOL and, recently, Google is comparatively more used elsewhere. However, that a $100 \%$ of my respondents use IM suggesting the obvious popularity of IM in Taiwan. 